\title{
Investigation of the Geographical Environment Impact on the Chemical Components of Peganum harmala L. through a Combined Analytical Method
}

\author{
Yinping Li, Hao Tian, Qing He,* Zhufeng Geng, Saixun Yan, Gulimeikereyi Tuniyazi, and Xi Bai
}

Cite This: ACS Omega 2021, 6, 25497-25505

ABSTRACT: By implementing NMR, inductively coupled plasma-atomic emission spectrometry (ICP-AES), and the UVvis spectroscopic techniques, metabolites, mineral elements, and antioxidant activities (DPPH) of Peganum harmala L. samples from Manasi and Fuhai of Xinjiang were studied in this research to investigate the geographical environment impact at the molecular level. First of all, partial least squares discriminant analysis was conducted to explore differential endogenous metabolites. A total of 18 metabolites were identified, and 14 mineral element contents were calculated quantitatively, which displayed diverse changing trends from these two origins. Valine, succinic acid, betaine, sucrose, and vasicine exhibited significant differences between these two groups as well as mineral nutrient profiles $(\mathrm{Mg}, \mathrm{Cu}, \mathrm{N}, \mathrm{K}$,

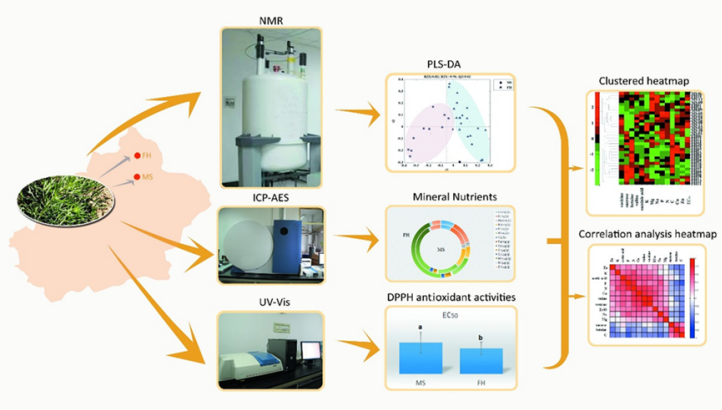
$\mathrm{Na}, \mathrm{P}, \mathrm{Zn}, \mathrm{C})$ and $\mathrm{DPPH}$ antioxidant activities $\left(\mathrm{EC}_{50}\right)$. The obvious different characteristics of chemical components and antioxidant activities in these two groups were further verified by heat map cluster analysis. Pearson correlation analysis also revealed the remarkable relationship of chemical components and antioxidant activities, which are strongly associated with the regional environment. This study showed that the combination of methodologies proposed will be highly useful in evaluating the environmental variation and diversity in terrestrial ecosystems.

\section{INTRODUCTION}

In recent years, studies on abiotic stress tolerance in plants have emerged as a research highlight in plant ecology. ${ }^{1}$ Antioxidant defense was considered to be a valuable mechanism that exhibits a significant role in the adaption of plants to high-stress environments. ${ }^{2}$ Under salt stress, the normal metabolic process as well as the dynamic balance of reactive oxygen species (ROS) production and ROS scavenging is disturbed. ${ }^{3}$ Excessive accumulation of ROS in plant cells occurred, and the cells were damaged through disabling functions of nucleic acids, changing the protein structure and affecting significant metabolic pathways. ${ }^{4}$ Meanwhile, studies have shown that essential minerals and nonessential nutrition elements influence plant growth, development, and physiology. ${ }^{5}$ It also regulates physiological and biochemical mechanisms, and as a result, in consequence, the formation and accumulation of primary and secondary metabolites are also affected. Previous research studies mostly focus on agricultural crop performance under abiotic stress. ${ }^{6}$ However, the performance of plant tolerance to drought and salinity in arid and semiarid regions is seldom studied.

Peganum harmala $\mathrm{L}$. is a perennial herbaceous plant of the Zygophyllaceae family that is widely distributed in the northwest and north regions of China. ${ }^{7}$ As a glabrous plant, it grows under arid and semiarid conditions, such as steppe areas and sandy soils. In particular, it is being considered as a wild pasture and for erosion control because of its strong competitive ability and tolerance to drought and salinity. Studies of $P$. harmala are mainly focused on medicinal bioactive components of this plant, such as quinazoline, $\beta$ carboline alkaloids, and flavonoids, due to the fungicidal, ${ }^{9,10}$ anti-influenza, ${ }^{11}$ anti-inflammatory, ${ }^{12}$ and antitumor activities. ${ }^{7,13,14}$ Studies of $P$. harmala have reported that the extracts, especially its methanol extract, demonstrated the highest antioxidant activity. ${ }^{15}$ In our previous research, ${ }^{16,17}$ we first proposed the NMR-based method for the metabolome profile depiction of $P$. harmala extracts from different organs as well as various grown stages.

Plant metabolomics technology is considered an effective tool for the qualitative and quantitative analyses of metabolites derived from a plant with a diverse genotype, phenotype,

Received: July 3, 2021

Accepted: September 14, 2021

Published: September 27, 2021 


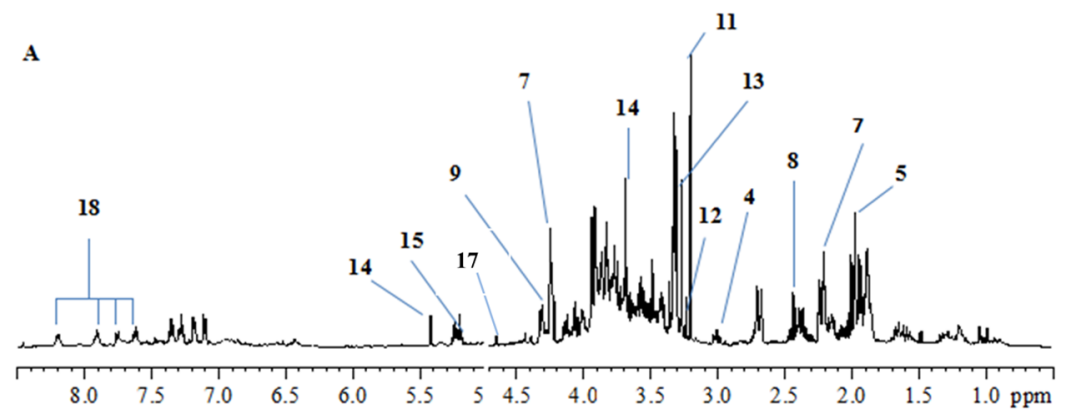

B

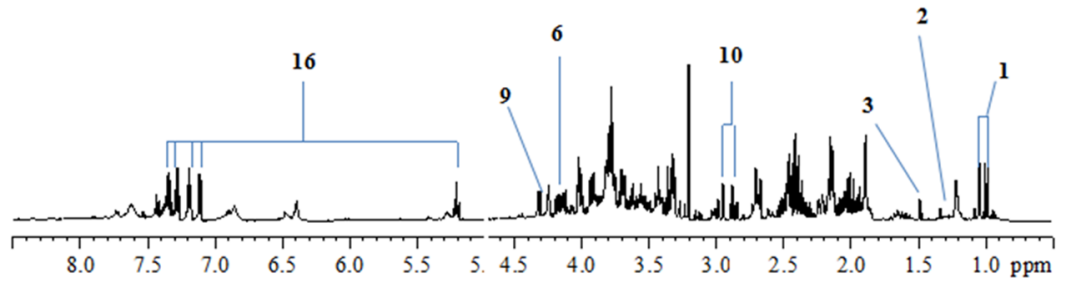

Figure 1. Representative ${ }^{1} \mathrm{H}$ NMR spectra of $P$. harmala from two origins: (A) Manasi (MS) and (B) Fuhai (FH). Several characteristic peaks are identified as 1, valine; 2, threonine; 3, alanine; 4, lysine; 5, acetic acid; 6, proline; 7, 4-hydroxyisoleucine; 8, succinic acid; 9, malic, acid; 10, asparagine; 11, choline; 12, phosphorylcholine; 13, betaine; 14, sucrose; $15, \beta$-glucose; 16, vasicine; 17, $\alpha$-glucose; and 18 , vasicinone.

Table 1. Most Common Metabolites Found in the P. harmala Extract by NMR Analysis ${ }^{a}$

\begin{tabular}{|c|c|c|c|c|}
\hline no. & compounds & formula & ${ }^{1} \mathrm{H}$ chemical shift & multiplicity \\
\hline 1 & valine & $\mathrm{C}_{5} \mathrm{H}_{11} \mathrm{NO}_{2}$ & $0.99,1.05,2.22,3.65$ & $(\mathrm{~d}),(\mathrm{d}),(\mathrm{m}),(\mathrm{m})$ \\
\hline 2 & threonine & $\mathrm{C}_{4} \mathrm{H}_{9} \mathrm{NO}_{3}$ & $3.57,4.25,1.33$ & $(\mathrm{~d}),(\mathrm{m}),(\mathrm{d})$ \\
\hline 3 & alanine & $\mathrm{C}_{4} \mathrm{H}_{9} \mathrm{NO}_{3}$ & $1.48,3.57$ & $(\mathrm{~d}),(\mathrm{q})$ \\
\hline 4 & lysine & $\mathrm{C}_{6} \mathrm{H}_{14} \mathrm{~N}_{2} \mathrm{O}_{2}$ & $1.65,1.89,2.25,3.02,3.60$ & $(\mathrm{~m}),(\mathrm{m}),(\mathrm{m}),(\mathrm{t})$ \\
\hline 5 & acetic acid & $\mathrm{C}_{6} \mathrm{H}_{14} \mathrm{~N}_{2} \mathrm{O}_{2}$ & 1.92 & (s) \\
\hline 6 & proline & $\mathrm{C}_{5} \mathrm{H}_{9} \mathrm{NO}_{2}$ & $1.96,2.03,2.38,4.12$ & $(\mathrm{~m}),(\mathrm{m}),(\mathrm{m}),(\mathrm{dd})$ \\
\hline 7 & 4-hydroxyisoleucine & $\mathrm{C}_{6} \mathrm{H}_{13} \mathrm{NO}_{3}$ & $4.25,3.31,2.22,1.8,3.95$ & \\
\hline 8 & succinic acid & $\mathrm{C}_{4} \mathrm{H}_{6} \mathrm{O}_{4}$ & 2.43 & $(\mathrm{~s})$ \\
\hline 9 & malic acid & $\mathrm{C}_{4} \mathrm{H}_{6} \mathrm{O}_{5}$ & $2.71,4.31$ & (dd), (dd) \\
\hline 10 & asparagine & $\mathrm{C}_{18} \mathrm{H}_{20} \mathrm{~N}_{2} \mathrm{O}_{3}$ & $4.03,2.94,2.84$ & $(\mathrm{dd}),(\mathrm{ddd}),(\mathrm{m})$ \\
\hline 11 & choline & $\mathrm{C}_{5} \mathrm{H}_{14} \mathrm{NO} . \mathrm{CHO}$ & 3.21 & (s) \\
\hline 12 & phosphorylcholine & $\mathrm{C}_{15} \mathrm{H}_{42} \mathrm{~N}_{3} \mathrm{O}_{7} \mathrm{P}$ & 3.23 & (s) \\
\hline 13 & betaine & $\mathrm{C}_{5} \mathrm{H}_{12} \mathrm{C}_{1} \mathrm{NO}_{2}$ & 3.27 & (s) \\
\hline 14 & sucrose & $\mathrm{C}_{12} \mathrm{H}_{22} \mathrm{O}_{11}$ & $4.06,3.69,4.22,5.42$ & $(\mathrm{t}),(\mathrm{s}),(\mathrm{m}),(\mathrm{d})$ \\
\hline 15 & $\beta$-glucose & $\mathrm{C}_{6} \mathrm{H}_{12} \mathrm{O}_{6}$ & 4.65 & (d) \\
\hline 16 & vasicine & $\mathrm{C}_{11} \mathrm{H}_{12} \mathrm{~N}_{2} \mathrm{O}$ & $5.20,7.12,7.36,7.28,7.20$ & $(\mathrm{t}),(\mathrm{dd}),(\mathrm{m}),(\mathrm{m}),(\mathrm{m})$ \\
\hline 17 & $\alpha$-glucose & $\mathrm{C}_{6} \mathrm{H}_{12} \mathrm{O}_{6}$ & 5.24 & (d) \\
\hline 18 & vasicinone & $\mathrm{C}_{11} \mathrm{H}_{10} \mathrm{~N}_{2} \mathrm{O}_{2}$ & $7.79,7.94,7.65,8.25$ & $(\mathrm{t}),(\mathrm{t}),(\mathrm{d}),(\mathrm{d})$ \\
\hline
\end{tabular}

${ }^{a}$ Multiplicity is indicated as follows: s, singlet; $\mathrm{d}$, doublet; $\mathrm{t}$, triplet; q, quartet; dd, doublet of doublets; and m, multiplet.

growth phase, etc. ${ }^{18}$ The chromatographic technique, mass spectrometry, and nuclear magnetic resonance were mostly the frequently applied approach to conduct high-throughput identification and efficient analysis of complex metabolites in metabolomics. ${ }^{19}$ As a quick, simple, and highly reproducible method, the ${ }^{1} \mathrm{H}$ NMR technique could simultaneously acquire all proton-bearing metabolites, irrespective of their volatility or polarity, and generate hundreds of peaks in one spectrum without an additional separation step. Furthermore, twodimensional and heteronuclear NMR techniques could be employed for structural identification as an auxiliary approach. However, there is no single analytical platform that could enable the whole metabolome due to the diverse sensitivity range and various types of samples detected. ${ }^{20}$ The introduced combined analytical platforms not only give the metabolome information with high diversity and extensive dynamic range but also provide a more accurate and less time-consuming strategy for metabolomics. ${ }^{21}$

In this study, different multivariate analytical technologies such as the nuclear magnetic resonance (NMR), ultraviolet and visible spectrophotometer (UV-vis), and inductively coupled plasma-atomic emission spectrometry (ICP-AES) were adopted to analyze metabolites, mineral elements, and antioxidant activities (DPPH) in P. harmala samples from Manasi (MS) and Fuhai (FH) of Xinjiang for the first time. Correlation analysis of these changes of metabolism from two geographical origins was systematically investigated, and the characteristic growing environment impact was also discussed. Therefore, our findings would enhance the chemical composition in $P$. harmala. With the multiplatform metabolomics methodology, we look to provide a novel insight and complete view on chemical profile characteristics of $P$. harmala 

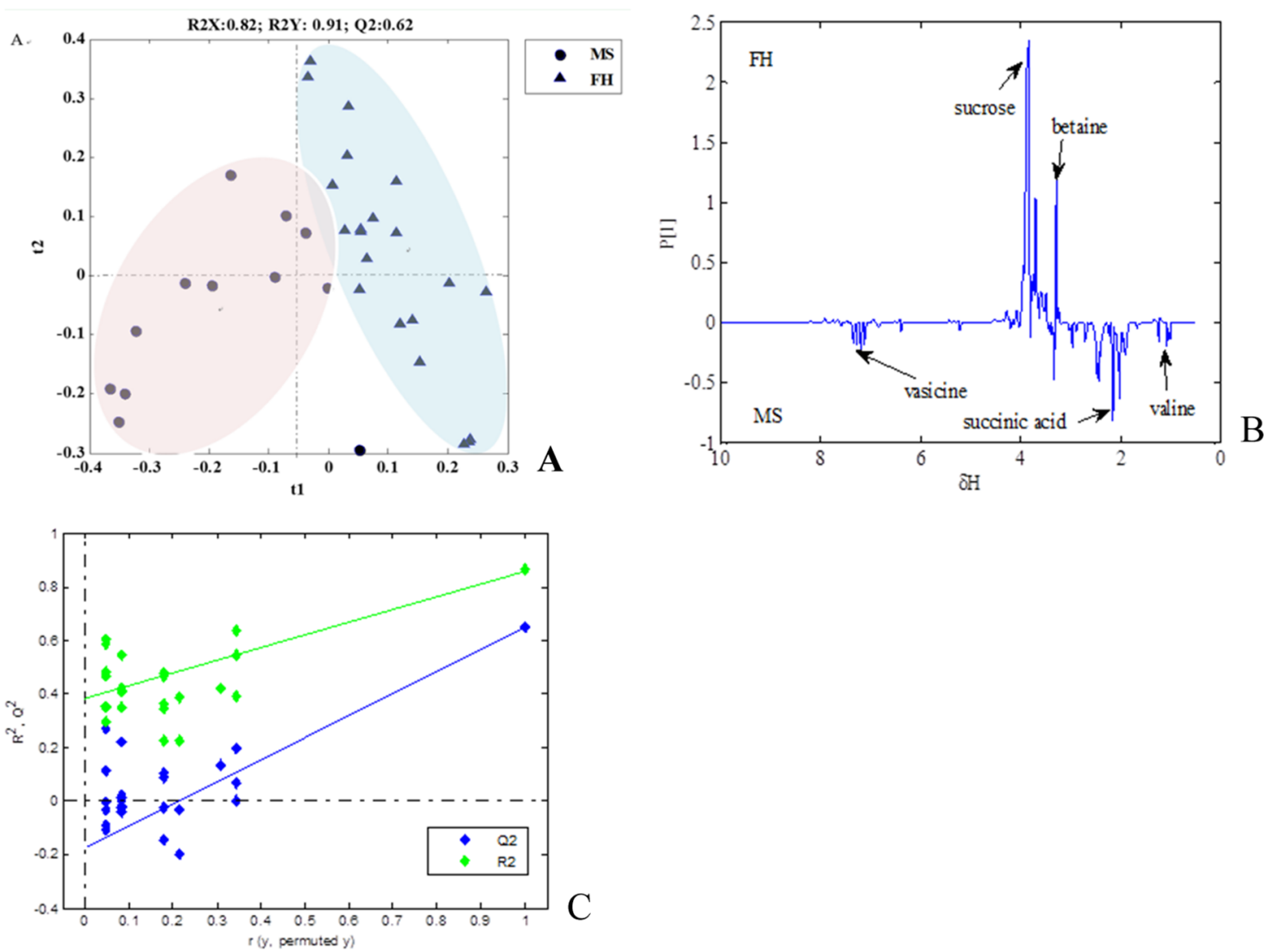

Figure 2. PLS-DA model of 33 observations and 468 variables, (A) score plot generated from the multivariate model of ${ }^{1} \mathrm{H}$ NMR spectra of Fuhai and Manasi P. harmala (Manasi: $\mathrm{MS}$, Fuhai: $\mathbf{\Delta F H}$; mean-scaled; R2X: 0.82, R2Y: 0.91, and Q2: 0.62). (B) Loading plot representing significant peaks, which are labeled as vasicine, sucrose, betaine, succinic acid, and valine. (C) Model validation test by 25 permutations of three components. Intercepts $R^{2}(0.00,0.38)$ and $Q^{2}(0.00,-0.20)$ do not exhibit model validity. Symbols: green tilted square solid, $R^{2}$ and blue-green tilted square solid, $Q^{2}$.

from these locations through the levels of mineral nutrients and antioxidant activities that reflect the physiological state of the studied organism in answer to a given environmental stress. The result will provide a theoretical basis and valuable reference for the environmental control of plant cultivation.

\section{RESULTS AND DISCUSSION}

2.1. Chemical Component Identification in ${ }^{1} \mathrm{H}$ NMR Spectra. ${ }^{1} \mathrm{H}$ NMR spectra comparison of $P$. harmala methanol extracts are shown in Figure 1 (one representative sample selected from each site revealed some differences between the two different sampling sites). Eighteen metabolites assigned from the selected $P$. harmala spectra were mostly amino acids, sugars, and some organic acids and alkaloids. ${ }^{16}$ Peaks in the spectral sugar region $(3.2-6.0 \mathrm{ppm})$ were obviously higher than that in the aliphatic and aromatic regions $(0.5-3.2 ; 6.0-$ $8.5 \mathrm{ppm})$. The following assignments are accomplished by comparing with the chemical shifts of standard substances using the PRIMe website, ${ }^{22}$ the Human Metabolome Database website, ${ }^{23}$ and our previous studies; ${ }^{16}$ meanwhile, the overlapping NMR signals were also confirmed by $2 \mathrm{D}$ NMR experiments. A total of 18 identified compounds are listed: alanine at $\delta_{\mathrm{H}}=1.48$; lysine at $\delta_{\mathrm{H}}=1.65,1.89,2.25,3.60$, and 3.02; 4-hydroxyisoleucine at $\delta_{\mathrm{H}}=4.25,3.95,3.31,1.80$, and 2.22; asparagine at $\delta_{\mathrm{H}}=2.84,2.94$, and 4.03; glucose at $\delta_{\mathrm{H}}=$ $3.20-3.91,4.65$, and 5.24; proline at $\delta_{\mathrm{H}}=1.96,2.03,2.38$, and 4.12; succinic acid at $\delta_{\mathrm{H}}=2.43$; choline at $\delta_{\mathrm{H}}=3.21$; betaine at $\delta_{\mathrm{H}}=3.27$; malic acid at $\delta_{\mathrm{H}}=4.31$; sucrose at $\delta_{\mathrm{H}}=3.41-4.18$ and 5.42; threonine at $\delta_{\mathrm{H}}=1.33$; and valine at $\delta_{\mathrm{H}}=0.99$ and 1.05. The characteristic peaks in the spectral aromatic region were auxiliary identified through two-dimensional (2D) NMR. The secondary metabolites, vasicine and vasicinone, were identified, showing very intense signals. The ${ }^{1} \mathrm{H}$ NMR spectrum of vasicine was reported ${ }^{24}$ (vasicine at $\delta_{\mathrm{H}}=7.12-$ 7.36, and vasicinone at $\left.\delta_{\mathrm{H}}=7.65-8.25\right)$. A total of 18 identified $P$. harmala metabolites were assigned and are listed in Table 1.

The characteristic peaks of metabolites without overlapping were adopted to quantify primary metabolites by integrating the intensity of protons compared with sodium 3-trimethylsilyl $\left[2,2,3,3-2 \mathrm{D}_{4}\right]$ propionate (TSP) on the extract weight basis. The concentration of the following metabolites, including sucrose, proline, betaine, lysine, succinic acid, 4-hydroxyisoleucine, valine, vasicine, and acetic acid, in two sample sites were calculated and are shown in Table 1.

2.2. Multivariate Data Analysis of the Spectral Dataset. The influence of the geographical origin on the $P$. harmala metabolome was further evaluated using the spectral dataset via the partial least squares discriminant analysis (PLSDA) model. In Figure 2A, samples collected from Fuhai and Manasi are clearly separated, which indicates that their metabolic profile patterns are distinguishable. The samples collected from Manasi were distributed in the negative region of PLS-DA t1, whereas the samples of Fuhai were in the positive region. The employed PLS-DA model was crossvalidated, and the model's goodness-of-fit was indicated by 
R2Y values; meanwhile, the model's predictive ability was assessed and presented by Q2 values. ${ }^{25}$ Generally, the range of the R2Y value is between 0 and $1, \mathrm{R} 2 \mathrm{Y}$ approaching 1 represents the model with a perfect fit. Furthermore, PLS-DA models with Q2 values larger than 0.5 are considered good. As demonstrated in Figure 2A, R2X, R2Y, and Q2 values of the generated PLS-DA model are 0.82, 0.91, and 0.62, respectively, which have shown that these models are robust and there is no statistical over-fitting of the PLS-DA model, which were successfully validated by the permutation test (Figure $2 \mathrm{C}$ ).

Discriminatory metabolites were found to contribute to the referred segregation pattern in the loading plot from Manasi and Fuhai groups. The result indicated that Manasi extracts contained higher levels of vasicine, valine, and succinic acid than Fuhai samples. Lower levels of sucrose and betaine were found in the Manasi group (Figure 2B). Statistical differences between MS and $\mathrm{FH}$ were observed in betaine, succinic acid, valine, vasicine $(p<0.01)$, and sucrose $(p<0.05)$. The VIP scores of the chosen metabolites and the calculated $p$-values are shown in Table S2.

2.3. Mineral Nutrient, Total $C$, and $N$ Contents of $P$. harmala. Two-way analysis of variance (ANOVA) was applied to evaluate the significance of differences in mineral nutrient levels between two origins. ANOVA indicated that all mineral nutrients with the exception of $\mathrm{Ca}, \mathrm{Fe}, \mathrm{Co}, \mathrm{Cr}, \mathrm{Mn}$, and $\mathrm{Ni}$ presented significantly different levels compared to Fuhai and Manasi groups. The mean concentrations of analyzed minerals and standard deviation are listed in Table 2 , and the ring diagram was used as a graphical representation in Figure S1. K, Na, and Ca exhibited higher concentrations in all analyzed samples; meanwhile, the other detected elements decreased in the following order $\mathrm{Mg}, \mathrm{P}$, and Fe. The mean contents of minor and trace elements decrease in the following order: $\mathrm{Mn}>\mathrm{Zn}>\mathrm{Cr}>\mathrm{Cu}>\mathrm{Ni}>\mathrm{Co}$. The Manasi group had the higher contents of $\mathrm{K}, \mathrm{Na}, \mathrm{P}, \mathrm{N}, \mathrm{Cu}$, and $\mathrm{Zn}$ but contained a lower concentration of the total carbon. The contents of residual elements were quite similar between these two districts, Fuhai and Manasi.

2.4. DPPH Radical-Scavenging Activity of $P$. harmala. The sample antioxidant activity was examined by the DPPH radical method. The $\mathrm{EC}_{50}$ value is the concentration of the extract needed to achieve a $50 \%$ decrease in absorbance. As the $\mathrm{EC}_{50}$ value represents an inhibitory concentration, a smaller $\mathrm{EC}_{50}$ value corresponds to greater antioxidant activity. As mentioned in previous studies, ${ }^{26}$ the higher levels of natural antioxidants produced from plant sources indicated the stronger antioxidant activity. The $\mathrm{EC}_{50}$ values of these samples at two sample sites were calculated through the mean contents of analyzed DPPH antioxidant activity and are presented in Table 2. A graphical representation of data is shown in Figure S2. A total of 33 samples from two locations were involved in this antioxidant activity assessment using the DPPH assay, and the results suggested that Fuhai methanol extracts $\left(\mathrm{EC}_{50}\right.$, $212.65 \pm 54.02 \mathrm{mg} / \mathrm{mL}$ ) show higher antioxidant activity than that of Manasi $\left(\mathrm{EC}_{50}, 263.53 \pm 87.78 \mathrm{mg} / \mathrm{mL}\right)$. The difference between these two groups exhibited significantly varied values $(P<0.05)$. These results demonstrated that Fuhai $P$. harmala samples with higher free radical-scavenging activity contained more antioxidant components than that of Manasi.

A total of 33 samples were used for analysis. The values, means \pm SD (MS: $n=12$, FH: $n=21$ ), in the same row with different lowercase showed statistically significant differences
Table 2. Mineral Nutrient Contents, Metabolite Levels, Antioxidant Activities of P. harmala ${ }^{a}$

\begin{tabular}{|c|c|c|}
\hline indices & MS & $\mathrm{FH}$ \\
\hline \multicolumn{3}{|c|}{ Mineral Element of $P$. harmala with Manasi and Fuhai } \\
\hline $\mathrm{Ca}(\mathrm{mg} / \mathrm{g})$ & $15.83 \pm 6.99$ & $14.37 \pm 4.12$ \\
\hline $\mathrm{K}(\mathrm{mg} / \mathrm{g})$ & $33.05 \pm 11.68 \mathrm{aA}$ & $24.24 \pm 5.69 \mathrm{bB}$ \\
\hline $\mathrm{Mg}(\mathrm{mg} / \mathrm{g})$ & $6.66 \pm 2.09 \mathrm{a}$ & $4.81 \pm 2.35 \mathrm{~b}$ \\
\hline $\mathrm{Na}(\mathrm{mg} / \mathrm{g})$ & $28.01 \pm 13.90 \mathrm{aA}$ & $12.18 \pm 9.15 b B$ \\
\hline $\mathrm{P}(\mathrm{mg} / \mathrm{g})$ & $1.40 \pm 0.59 \mathrm{aA}$ & $0.72 \pm 0.30 \mathrm{bB}$ \\
\hline $\mathrm{N}(\mathrm{mg} / \mathrm{g})$ & $31.78 \pm 7.29 \mathrm{aA}$ & $23.20 \pm 3.92 \mathrm{bB}$ \\
\hline $\mathrm{C}(\mathrm{mg} / \mathrm{g})$ & $353.44 \pm 14.32 \mathrm{bB}$ & $389.06 \pm 17.21 \mathrm{aA}$ \\
\hline $\mathrm{Fe}(\mathrm{mg} / \mathrm{g})$ & $0.56 \pm 0.27$ & $0.58 \pm 0.28$ \\
\hline Co $(\mu \mathrm{g} / \mathrm{g})$ & $0.49 \pm 0.37$ & $0.68 \pm 0.32$ \\
\hline $\mathrm{Cr}(\mu \mathrm{g} / \mathrm{g})$ & $6.46 \pm 1.76$ & $7.07 \pm 2.04$ \\
\hline $\mathrm{Cu}(\mu \mathrm{g} / \mathrm{g})$ & $5.67 \pm 1.84 \mathrm{aA}$ & $3.94 \pm 1.16 \mathrm{bB}$ \\
\hline $\operatorname{Mn}(\mu \mathrm{g} / \mathrm{g})$ & $76.48 \pm 30.97$ & $81.08 \pm 53.21$ \\
\hline $\mathrm{Ni}(\mu \mathrm{g} / \mathrm{g})$ & $2.35 \pm 0.85$ & $2.10 \pm 0.84$ \\
\hline $\mathrm{Zn}(\mu \mathrm{g} / \mathrm{g})$ & $16.32 \pm 6.38 \mathrm{aA}$ & $9.61 \pm 7.18 \mathrm{bB}$ \\
\hline \multicolumn{3}{|c|}{$\begin{array}{l}\text { Antioxidant Activity by DPPH Radical-Scavenging Power Assay Expressed a } \\
\mathrm{mg} / \mathrm{L}\end{array}$} \\
\hline $\mathrm{EC}_{50}$ & $263.53 \pm 87.78 a$ & $212.65 \pm 54.02 \mathrm{~b}$ \\
\hline \multicolumn{3}{|c|}{ Metabolite Levels in Methanol Extract of $P$. harmala $\mathrm{mg} / \mathrm{g}$} \\
\hline sucrose & $27.99 \pm 18.20 \mathrm{~b}$ & $55.83 \pm 37$ a \\
\hline proline & $60.89 \pm 31.77$ & $56.54 \pm 27.80$ \\
\hline betaine & $2.75 \pm 1.54 \mathrm{bB}$ & $5.94 \pm 2.24 \mathrm{aA}$ \\
\hline lysine & $56 \pm 29.12$ & $59.33 \pm 36.73$ \\
\hline succinic acid & $3.44 \pm 1.83 \mathrm{aA}$ & $2.19 \pm 1.56 \mathrm{bB}$ \\
\hline 4-hydroxyisoleucine & $143.61 \pm 44.44$ & $155.66 \pm 80.19$ \\
\hline valine & $8.12 \pm 5.59 \mathrm{aA}$ & $3.16 \pm 1.2 \mathrm{bB}$ \\
\hline vasicine & $76.05 \pm 34.39$ aA & $45.38 \pm 17.83 \mathrm{bB}$ \\
\hline acetic acid & $2.63 \pm 0.77$ & $2.08 \pm 0.64$ \\
\hline
\end{tabular}

${ }^{a}$ Mean \pm standard deviation (SD). The unit of $\mathrm{Ca}, \mathrm{K}, \mathrm{Mg}, \mathrm{Na}, \mathrm{P}, \mathrm{N}$, $\mathrm{C}$, and $\mathrm{Fe}$ is $\mathrm{mg} / \mathrm{g}$; those of $\mathrm{Cr}, \mathrm{Mn}, \mathrm{Ni}$, and $\mathrm{Zn}$ are $\mu \mathrm{g} / \mathrm{g}$.

$(P<0.05)$ and the values labeled with different capital letters represent extremely significant difference $(P<0.01)$ according to the Kruskal-Wallis test, the same as below.

2.5. Correlation of Metabolites, Mineral Nutrients, and DPPH. To evaluate the discriminative ability of the identified chemical markers with a significant difference, mineral nutrients, and DPPH antioxidant activity, the heat maps were employed based on 14 tested biological markers to visualize the variation in all samples at the molecular level (Figure 3A). In this map, the color shade displays different levels of chemical compositions: the redder and greener colors correspond to the higher or lower concentration, respectively. The positive value indicates a higher level than the mean concentration, and the negative value below zero means a lower level. Hence, data visualization was conducted for a comprehensive understanding of chemical composition distribution in significant differences. As a result, the relative trending of chemical composition in all examined samples is demonstrated in Figure 3A. The heat map clearly indicates that there are high chemical heterogeneities. Remarkably, among the identified marker compounds, metabolites, including vasicine, valine, and succinic acid, and mineral nutrients, such as $\mathrm{K}, \mathrm{Mg}, \mathrm{Na}, \mathrm{P}, \mathrm{N}, \mathrm{Cu}$, and $\mathrm{Zn}$, the $\mathrm{DPPH}$ antioxidant activity was mainly distributed in MS. Similarly, FH was featured through the presence of the following three chemical components: sucrose, betaine, and $\mathrm{C}$. In view of the fact that the DPPH test offered the ability of a substance to scavenge free radicals, it indicates that these detected compounds in 


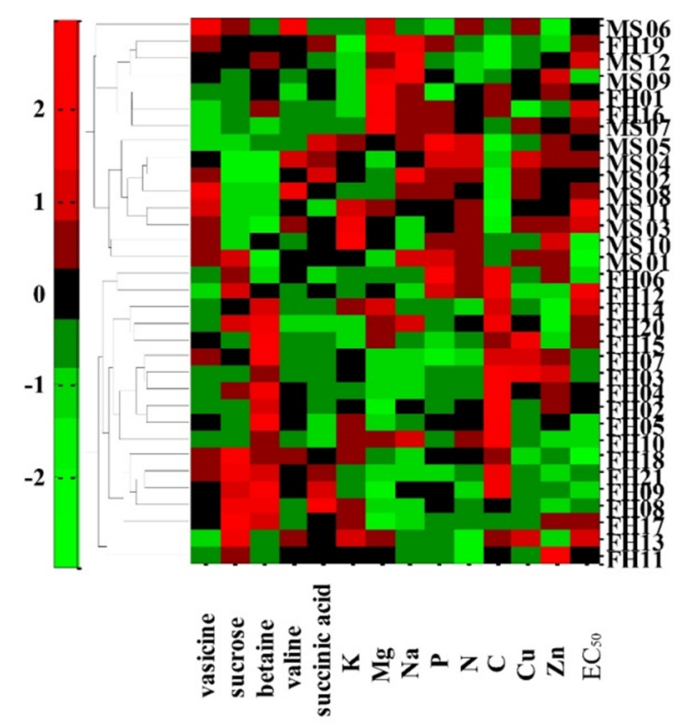

A

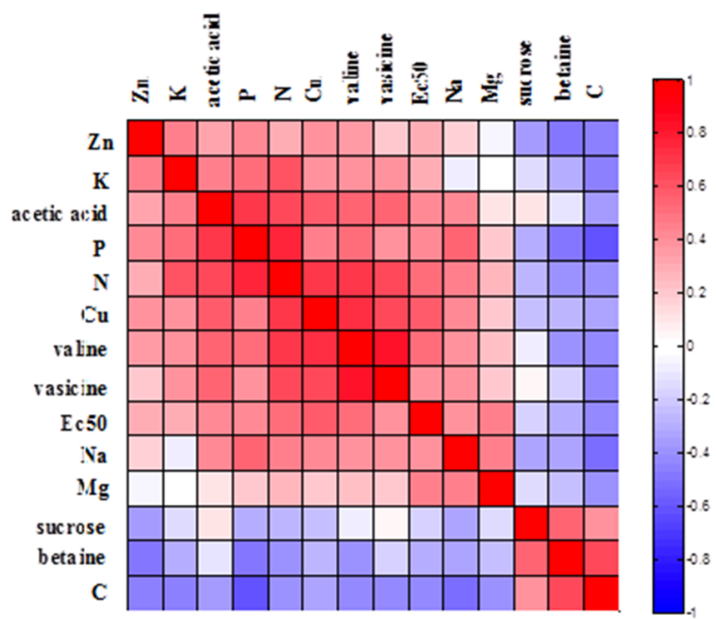

B

Figure 3. Clustered heat map and correlation analysis. (A) Clustered heat map of 13 characteristic components and antioxidant activity $\mathrm{EC}_{50}$ in the methanol extract from two regions (MS: Manasi; FH: Fuhai; positive correlation (red) and negative correlation (green)). The hierarchical tree was generated by applying the Euclidean distance metric and average linkages. (B) Correlation analysis shows the correlation between these chemical compositions and $\mathrm{EC}_{50}$ values for two groups. It is a pseudocolor map, and the colors symbolize Pearson's correlation coefficient values (positive correlation (red) and negative correlation (blue)).

Fuhai and Manasi displayed different scavenging and reducing activities.

The Pearson's correlation among metabolites, mineral nutrients, and DPPH inhibiting power is given in Figure 3. In the correlation map, variables are colored and reordered according to the $k$-nearest neighbor (KNN) method. It is regarded as a strong correlation if the absolute value of the correlation coefficient is near 1 . The results indicated a positive correlation between $\mathrm{Zn}, \mathrm{K}, \mathrm{P}, \mathrm{N}, \mathrm{Cu}$, acetic acid, valine, vasicine, and $\mathrm{EC}_{50}$ antioxidant activities. A negative correlation was detected in sucrose, betaine, and C, which shows contradictory results. As indicated, the similar trend between the changes of sucrose, betaine, and $\mathrm{C}$ may suggest that they are associated with each other in biochemical metabolic pathways.

2.6. Discussion. The factors accounting for the discrimination between $P$. harmala from the two sites are probably complicated and could be relevant to environmental conditions, for instance, climate, soil type, or fertilization. ${ }^{5}$ Fuhai and Manasi are located in northwest China with similar geographical factors and climatic conditions, such as altitude (239-525 m), longitude $\left(85^{\circ} 17^{\prime} 41^{\prime \prime}\right.$ to $\left.87^{\circ} 41^{\prime} 28^{\prime \prime} \mathrm{E}\right)$, and latitude $\left(44^{\circ} 29^{\prime}\right.$ to $\left.47^{\circ} 24^{\prime} 24^{\prime \prime} \mathrm{N}\right)$. Fuhai shows a wide distribution of meadow soil belonging to the pastoral area, whereas Manasi mainly consists of gray desert soil, desert soil, and saline soil belonging to the agricultural area. These distinct environmental conditions are known to have a significant influence on metabolite generation. In the field environment, plants have evolved self-defense and protective mechanisms to deal with abiotic stress. Known strategies in stress physiology contain adjusting osmotic potential to protect the subcellular structure through organic solutes and inorganic ion accumulation, ${ }^{27}$ repairing oxidative balance to avoid further damage caused by the increase in reactive oxygen species (ROS) and regulating cell-membrane fluidity by cell wall alteration. ${ }^{28}$
In our study, by comparing Manasi and Fuhai $P$. harmala samples, the sodium content had a greater accumulation level in Manasi more than in Fuhai. Additional comparative analysis implied that large variation like metabolite concentrations exists between the two sampling sites-Fuhai and Manasi (Table 2). The metabolite levels such as succinic acid, valine, and vasicine were higher in Manasi than in Fuhai. At present, the widespread studies of salt stress responses have been interpreted for Suaeda corniculata ${ }^{29}$ and Atriplex halimus ${ }^{30}$ and salt stress is known to increase succinic acid and valine contents. Our investigation was consistent with the studies mentioned above. In contrast, Manasi $P$. harmala had lower sucrose and betaine than Fuhai samples. High salt concentrations could improve the production of secondary metabolites such as vasicine.

In $P$. harmala, ROS is continuously generated as by-products under extensive metabolic pathways, and simultaneously it is also scavenged by diverse antioxidative substances. ${ }^{31}$ Because high concentrations of ROS may lead to plant cell damage, ${ }^{32}$ the imbalance of ROS generation and elimination due to salt stress should be restored. The stronger scavenging activity to DPPH free radicals in Fuhai $P$. harmala methanol extracts reflects elevated antioxidant components as the salt-tolerance mechanism of $P$. harmala probably increases the levels and enhances the activities of antioxidative substances to maintain oxidative balance under salinity stress. The correlation analysis result showed a negative relationship between sucrose, betaine, total carbon, and the $\mathrm{EC}_{50}$ value. The increased betaine concentration would be contributed to soluble saccharide accumulation and enhanced antioxidant activity, as reported previously. The detected variation of the identified compounds allowed an insight into the mechanism of plant tolerance to salt-induced oxidative stress at the molecular level. ${ }^{33,34}$ These results indicated that the injurious effects of salt stress on $P$. harmala growth were severe, which was consistent with previous reports. ${ }^{35}$ 
To improve crop productivity and ensure food security, the over-application of chemical fertilizers was found in some agricultural areas of northwest Xinjiang. Manasi, as the biggest artificial oasis, is positioned in the major agricultural region. Less than $20 \%$ of chemical fertilizers can be fully absorbed by crops during the growth stage. Meanwhile, more than $50 \%$ of the chemical fertilizer would be brought into soil circulation, and the discarded chemicals may cause harmful effects to the surrounding ecological environment like groundwater. In this study, the Manasi samples were found to contain higher total $\mathrm{N}, \mathrm{K}$, and $\mathrm{P}$ contents. This may suggest that the incorrect usage of chemical fertilizers led to excess $\mathrm{N}, \mathrm{P}$, and $\mathrm{K}$ absorption of $P$. harmala. The nutrient enrichment of the available $\mathrm{K}, \mathrm{P}$, and $\mathrm{N}$ in the $P$. harmala from the Manasi area was found, and it was remarkably positively correlated with the DPPH radical and antioxidative activities of $P$. harmala.

As a pastoral area, Fuhai is mainly based on animal husbandry, and natural organic fertilizers have been applied to the meadow soil. This better facilitates the procedure of carbon dioxide assimilation, which could be verified by a high level of the total $\mathrm{C}$ content of $P$. harmala in Fuhai. The organic fertilizers also promote absorbing these essential trace elements such as $\mathrm{Fe}, \mathrm{Zn}$, and $\mathrm{Mn}$ as well as provide nutrients for microorganisms around the rhizosphere. ${ }^{36}$ P. harmala in Fuhai had negative correlations between the contents of $\mathrm{C}$, betaine, sucrose, and DPPH antioxidative activities. Typically, $\mathrm{K}$ and $\mathrm{Mg}$ have significant functions in sugar and carbohydrate generation, transportation, and storage. The combined methodologies of the ${ }^{1} \mathrm{H}$ NMR technique and the ICP test along with canonical correlation analysis offered another perspective to demonstrate the function of mineral nutrients in plant metabolomics.

In addition, the total antioxidant effect would be influenced by various antioxidant species related to each other, which was defined as the synergistic effect. The interaction of a variety of antioxidants generated by $P$. harmala plays a more important role in plant response to ecological environment conditions. ${ }^{28}$ Plant acclimation to abiotic stimulation like drought and salt stress is crucial for growth and development in the field environment.

\section{CONCLUSIONS}

In this work, we first investigated metabolite variation between Manasi and Fuhai by the NMR-based plant metabolomics approach and then compared mineral nutrients and antioxidant activities, which are closely relevant to local soil environment variations. A total of 5 characteristic metabolites (valine, betaine, succinic acid, sucrose, and vasicine) and 8 mineral elements ( $\mathrm{K}, \mathrm{Mg}, \mathrm{Na}, \mathrm{P}, \mathrm{N}, \mathrm{Cu}, \mathrm{Zn}$, and $\mathrm{C}$ ) accounting for the major difference in geographical sites were screened out. The antioxidant activity was higher in Fuhai $P$. harmala samples, indicating that more endogenous antioxidants were synthesized than that of Manasi, and the correlation analysis result suggested that metabolites like sucrose, betaine, and total carbon may be involved in plant-source antioxidant production. This study revealed the relationship between metabolites, mineral nutrient changes, and antioxidant activities in $P$. harmala between the two types of ecological areas. This combined metabolomics approach could be extensively used to give a comprehensive understanding of the correlation between bioactivities and changes in metabolites and mineral nutrients under geographical variations.

\section{EXPERIMENTAL SECTION}

4.1. Chemicals. All chemicals in the digestion procedure were of the analytical-reagent grade obtained from J\&K Scientific Ltd. (Beijing, China). Concentrated nitric acid was used for sample digestion. High purity water (resistivity 18.2 $\mathrm{M} \Omega / \mathrm{cm}$ ) obtained using a Milli-Q purification system (Millipore Corp.) was used in solution preparation. Analytical grade methanol, sodium azide, disodium hydrogen phosphate dodecahydrates $\left(\mathrm{Na}_{2} \mathrm{HPO}_{4} \cdot 12 \mathrm{H}_{2} \mathrm{O}\right)$, and sodium dihydrogen phosphate dihydrate $\left(\mathrm{NaH}_{2} \mathrm{PO}_{4} \cdot 2 \mathrm{H}_{2} \mathrm{O}\right)$ were purchased from Nanjing Chemical Reagent Co., Ltd (Nanjing, China). Stock solutions $(1 \mathrm{mg} / \mathrm{mL}$ in $1 \%$ nitric acid) of elements $\mathrm{Ca}, \mathrm{Mg}, \mathrm{K}$, $\mathrm{Na}, \mathrm{P}, \mathrm{Co}, \mathrm{Cr}, \mathrm{Cu}, \mathrm{Fe}, \mathrm{Ni}, \mathrm{Mn}$, and $\mathrm{Zn}$ were used to prepare working standard solutions, which were obtained from the National nonferrous metal and electronic materials analysis and testing center (Beijing, China). Deuterium oxide $\left(\mathrm{D}_{2} \mathrm{O}\right.$, 99.9\% D), 1,1-diphenyl-2-picrylhydrazyl (DPPH), and sodium 3-trimethylsilyl $\left[2,2,3,3-2 \mathrm{D}_{4}\right]$ propionate (TSP) were purchased from J\&K Scientific Ltd. (Beijing, China).

4.2. Sampling Collection. The whole aerial parts of the $P$. harmala plant, except for seeds and flowers, were taken as the testing samples for our study. The samples were collected from Manasi $\left(44^{\circ} 29^{\prime} 26^{\prime \prime}\right.$ to $46^{\circ} 10^{\prime} 29^{\prime \prime} \mathrm{E}, 85^{\circ} 47^{\prime} 19^{\prime \prime}$ to $86^{\circ} 22^{\prime} 24^{\prime \prime} \mathrm{N}$ ) and Fuhai $\left(47^{\circ} 0^{\prime} 34^{\prime \prime}\right.$ to $47^{\circ} 24^{\prime} 24^{\prime \prime} \mathrm{E}, 87^{\circ} 17^{\prime} 25^{\prime \prime}$ to $\left.87^{\circ} 41^{\prime} 28^{\prime \prime} \mathrm{N}\right)$, Xinjiang District, China, in October 2013. These two areas have been recognized as the traditional agricultural region and the typical pasturing region, respectively, and their altitudes are 460-525 meters above sea level. The samples were authenticated by Professor Jin Li from the School of Life Sciences of Xinjiang Normal University. A voucher specimen has been deposited in the herbarium of the institute (voucher specimen number: 14926). After carefully cleaning with deionized water, the samples were dried to constant weight in air and then ground into a homogeneous powder with an electric grinder (Braun Melsungen, Melsungen, Germany). The powder samples collected at Manasi were labeled as group MS, and those collected at Fuhai were labeled as group FH. Detailed information of samples is listed in Table S1.

4.3. NMR Experiments. 4.3.1. Sample Preparation. The sample processing procedure is described in detail in our previous study. ${ }^{16}$ Briefly, before NMR analysis, $2000 \mathrm{mg}$ of dried powder sample and $12 \mathrm{~mL}$ of methanol were added to a centrifuge tube and then the mixture was vortexed and sonicated. The process was repeated three times. After vacuum rotatory evaporation, $10 \mathrm{mg}$ of lyophilized sample was redissolved in $300 \mu \mathrm{L}$ of phosphate buffer saline with an additional $200 \mu \mathrm{L}$ of $\mathrm{D}_{2} \mathrm{O}$ (containing $2 \mathrm{mM}$ sodium 3trimethylsilyl $\left[2,2,3,3-2 \mathrm{D}_{4}\right]$ propionate (TSP) as an intensity reference for ${ }^{1} \mathrm{H}$ spectra). Another $200 \mu \mathrm{L}$ of sodium azide solution $(10 \mathrm{mM})$ was added, and the total volume reached $700 \mu \mathrm{L}$. All solutions were vortexed with a micropipette and transferred into $2 \mathrm{~mL}$ Eppendorf centrifugal tubes. They were then centrifuged at $16000 \mathrm{~g}$ for $20 \mathrm{~min}$, and $600 \mu \mathrm{L}$ of supernatant was transferred to NMR tubes.

4.3.2. Spectral Collection. All NMR experiments were tested on a Bruker DRX-500 NMR spectrometer with a $5 \mathrm{~mm}$ BBFO probe at $298 \mathrm{~K}$. Solvent signal suppression was performed by applying the ${ }^{1} \mathrm{H}$ presaturation scheme with the $1 \mathrm{D}$-NOESY pulse. Then, 256 transients with $32 \mathrm{k}$ data points were recorded and it covered a spectral width of $5001.56 \mathrm{~Hz}$ with a relaxation delay of $2.0 \mathrm{~s}$. Major metabolites of the 
representative $P$. harmala sample were recognized through comparing with the literature studies, ${ }^{26,37}$ PRIMe website, ${ }^{22,38}$ and the Human Metabolome Database website. ${ }^{23}$ For auxiliary signal assignments, 2D TOCSY, HSQC, and HMBC ${ }^{39}$ experiments were acquired for the selected samples as an additional identification method, and the identified resonances are listed in Table 1.

The $33{ }^{1} \mathrm{H}$ NMR spectrum generated from the crude extract of $P$. harmala samples was imported in MestReNova software (version 8.1.2) and then processed by applying phase correction and baseline correction.

4.4. Elemental Determination. Sample preparation: Multielements were extracted using acid digestion in the Teflon vessel system under high pressure and temperature. ${ }^{35}$ Briefly, $100 \mathrm{mg}$ of sample was digested with $2 \mathrm{~mL}$ of $\mathrm{HNO}_{3}$ in closed-Teflon vessels for $5 \mathrm{~h}$ at $165^{\circ} \mathrm{C}$. The liquid sample was then added to $10 \mathrm{~mL}$ of ultrapure water after cooling. Subsequently, major ( $\mathrm{Ca}, \mathrm{Mg}, \mathrm{K}, \mathrm{Na}$, and $\mathrm{P}$ ) and trace (Co, $\mathrm{Cr}, \mathrm{Cu}, \mathrm{Fe}, \mathrm{Zn}, \mathrm{Mn}$, and $\mathrm{Ni}$ ) elements were examined by inductively coupled plasma emission spectroscopy (SPECTRO ARCOS EOP, SPECTRO Analytical Instruments $\mathrm{GmbH}$, America).

For $\mathrm{C}$ and $\mathrm{N}$ analysis, about $3 \mathrm{mg}$ of sample powder was analyzed. The concentrations of $\mathrm{C}$ and $\mathrm{N}$ were measured using the combustion method coupled with adsorption column separation on a CHN Elemental Analyzer (VARIO EL, Milan, Italy).

4.5. Determination of DPPH Radical-Scavenging Activity. The DPPH assay is extensively used for antioxidant activity assessment for its good reproducibility and less affected by external factors. Simplicity and high sensitivity make it to be a reliable method for natural antioxidants. ${ }^{40}$ The antioxidant scavenging activity of $P$. harmala methanol extracts was implemented according to the scavenging activity of the 1,1diphenyl-2-picrylhydrazyl-free radical (DPPH) as described by Williams $^{36}$ with slight modifications: $0.2 \mathrm{~mL}$ of different concentrations of $P$. harmala methanol extracts were mixed with an equal volume of a $23.4 \mu \mathrm{g} / \mathrm{mL} \mathrm{DPPH}$ methanolic solution. After shaking vigorously, the mixtures were left standing at room temperature in the dark for $30 \mathrm{~min}$. The absorbances of the resulting solutions were analyzed at $516 \mathrm{~nm}$ after $30 \mathrm{~min}$ using a UV-visible spectrophotometer (SPECORD200, Analytik Jena, Germany). The antioxidant activities were expressed as $\mathrm{EC}_{50}(\mathrm{mg} / \mathrm{mL})$, the concentration required to generate 50\% DPPH inhibition.

4.6. Data Analysis. 4.6.1. Multivariate Data Analysis. The solvent (water) region of $\delta_{\mathrm{H}} 5.05-4.70$ was removed from the whole spectra, and then the remaining spectral region $\left(\delta_{\mathrm{H}}\right.$ $0.5-10)$ was cut into 0.02 -ppm bins. The normalization step was accomplished by taking the entire spectral region as a reference. After that, the data was exported, including 458 variables, and the resulting ASCII files were further imported into MATLAB (R2010a; Mathworks, Inc.). All of these data were mean-centered before multivariate analysis.

Relative quantification was conducted using the nonoverlapped characteristic resonances of identified metabolites in spectra through the proton intensity integration compared with TSP on the extract weight basis. The resulting data were then subjected to multivariate analysis using SPSS Statistics software (SPSS, Inc., Chicago, IL). Differences between the groups were evaluated by the independent-sample T-test or Mann-Whitney $U$ test (nonparametric variables), which is performed using MATLAB software. Statistical significance of the data was determined at $p<0.05 .{ }^{1} \mathrm{H}$ NMR data were analyzed by PLS-DA and loading, and VIP plots were elicited to reveal these variables with class discriminating power. The goodness-of-fit $R^{2}$ and the predictive ability $Q^{2}$ values were used to depict the quality of models.

4.6.2. Univariate Data Analysis. All of the mineral nutrients, $\mathrm{EC}_{50}$, and selected metabolite concentrations in the specimens were compared between the two areas using nonparametric tests (Kruskal-Wallis) and then followed by post-hoc pairwise multiple comparisons, which were conducted using the Student-Newman-Keuls significant difference test. The $P$-value that is smaller than 0.05 or 0.01 was regarded as a statistically significant difference and extremely significant difference. All statistical values were calculated using the Statistical Package for the Social Sciences (SPSS, Chicago, IL) program. The results were expressed as mean values \pm standard deviation (SD).

The R's built-in function cor() was used to generate a canonical correlation between the metabolites, mineral nutrients, and $\mathrm{EC}_{50}$ with a significant statistical difference. Due to the non-normal distribution observed, KNN (k-nearest neighbor method) was conducted to verify the rate of classification. Spearman's correlations were also used to demonstrate correlations between different parameters. All of these chemometric analyses were performed using commercial software Matlab 2012b (The Mathworks Inc., Natick, MA). Pearson's correlation coefficients were calculated for selected mineral nutrients, metabolites, and $\mathrm{EC}_{50}$.

\section{ASSOCIATED CONTENT}

\section{Supporting Information}

The Supporting Information is available free of charge at https://pubs.acs.org/doi/10.1021/acsomega.1c03420.

Background data and analyzed DPPH values of $P$. harmala samples (Table S1); mineral nutrient contents, metabolite levels, antioxidant activities of $P$. harmala samples (Table S2); ring diagram for analysis of mineral elements in $P$. harmala samples from $\mathrm{MS}$ and $\mathrm{FH}$ (Figure S1); bar chart of $\mathrm{EC}_{50}$ analysis of $\mathrm{DPPH}$ antioxidant activity in P. harmala samples of $\mathrm{MS}$ and $\mathrm{FH}$ regions (Figure S2) (PDF)

\section{AUTHOR INFORMATION}

\section{Corresponding Author}

Qing He - School of Chemical Engineering and Technology, Tianjin University, Tianjin 300350, China; Phone: 18920737062; Email: 146155@tju.edu.cn

\section{Authors}

Yinping Li - College of Chemistry and Chemical Engineering, Xinjiang Normal University, Urumqi 830054, China; (1) orcid.org/0000-0003-4955-6133

Hao Tian - College of Chemistry and Chemical Engineering, Xinjiang Normal University, Urumqi 830054, China

Zhufeng Geng - Analytic and Testing Center, Beijing Normal University, Beijing 100875, China

Saixun Yan - Scientific Research Department, Xinjiang Normal University, Urumqi 830054, China

Gulimeikereyi Tuniyazi - College of Chemistry and Chemical Engineering, Xinjiang Normal University, Urumqi 830054, China 
Xi Bai - College of Chemistry and Chemical Engineering,

Xinjiang Normal University, Urumqi 830054, China

Complete contact information is available at:

https://pubs.acs.org/10.1021/acsomega.1c03420

\section{Author Contributions}

This manuscript was written through the contributions of all authors.

\section{Funding}

This work was supported by grants from the start fund for the Natural Science Foundation of Xinjiang Uygur Autonomous Region (2020D01A78), the Doctoral Foundation of Xinjiang Normal University (XJNUBS1901), and the Xinjiang Characteristic Medicine Edible Plant Resource Chemistry Laboratory Opening Project (KSUZDSYS202004).

\section{Notes}

The authors declare no competing financial interest.

\section{ACKNOWLEDGMENTS}

The authors wish to thank Professor Jin Li from the School of Life Sciences of Xinjiang Normal University for sample identification.

\section{REFERENCES}

(1) Feng, Z.; Ding, C.; Li, W.; Wang, D.; Cui, D. Applications of Metabolomics in the Research of Soybean Plant under Abiotic Stress. Food Chem. 2020, 310, No. 125914

(2) Jaleel, C. A.; Riadh, K.; Gopi, R.; Manivannan, P.; Inès, J.; AlJuburi, H. J.; Chang-Xing, Z.; Hong-Bo, S.; Panneerselvam, R. Antioxidant Defense Responses: Physiological Plasticity in Higher Plants under Abiotic Constraints. Acta Physiol. Plant 2009, 31, 427436.

(3) Jaleel, C. A.; Gopi, R.; Manivannan, P.; Panneerselvam, R. Responses of Antioxidant Defense System of Catharanthus roseus (L.) G. Don. to Paclobutrazol Treatment under Salinity. Acta Physiol. Plant 2007, 29, 205-209.

(4) Hossain, M. S.; Dietz, K. Tuning of Redox Regulatory Mechanisms, Reactive Oxygen Species and Redox Homeostasis under Salinity Stress. Front. Plant Sci. 2016, 7, 1-14.

(5) Watanabe, M.; Ohta, Y.; Licang, S.; Motoyama, N.; Kikuchi, J. Profiling Contents of Water-Soluble Metabolites and Mineral Nutrients to Evaluate the Effects of Pesticides and Organic and Chemical Fertilizers on Tomato Fruit Quality. Food Chem. 2015, 169, 387-395.

(6) Sun, C. X.; Li, M. Q.; Gao, X. X.; Liu, L. N.; Wu, X. F.; Zhou, J. H. Metabolic Response of Maize Plants to Multi-factorial Abiotic Stresses. Plant Biol. 2016, 18, 120-129.

(7) Khlifi, D.; Sghaier, R. M.; Amouri, S.; Laouini, D.; Hamdi, M.; Bouajila, J. Composition and Anti-oxidant, Anti-cancer and Antiinflammatory Activities of Artemisia Herba-alba, Ruta chalpensis L. and Peganum harmala L. Food Chem. Toxicol. 2013, 55, 202-208.

(8) Ma, J.; Wang, X. L. The Species and Distribution of Genus Peganum L. in the Desert Area of China. J. Desert Res. 1998, 18, 3641.

(9) Sarpeleh, A.; Sharifi, K.; Sonbolkar, A. Evidence of Antifungal Activity of Wild Rue (Peganum harmala L.) on Phytopathogenic Fungi. J. Plant Dis. Prot. 2009, 116, 208-213.

(10) Nenaah, G. Antibacterial and Antifungal Activities of (Beta)carboline Alkaloids of Peganum harmala (L) Seeds and Their Combination Effects. Fitoterapia 2010, 81, 779-782.

(11) Moradi, M. T.; Karimi, A.; Rafieian-Kopaei, M.; Fotouhi, F. In vitro Antiviral Effects of Peganum harmala Seed Extract and Its Total Alkaloids Against Influenza Virus. Microb. Pathog. 2017, 110, 42-49.

(12) Edziri, H.; Marzouk, B.; Mabrouk, H.; Garreb, M.; Douki, W.; Mahjoub, A.; Verschaeve, L.; Najjar, F.; Mastouri, M. Phytochemical Screening, Butyrylcholinesterase Inhibitory Activity and Anti-inflam- matory Effect of some Tunisian Medicinal Plants. S. Afr. J. Bot. 2018, $114,84-88$.

(13) Li, S.; Cheng, X.; Wang, C. A Review on Traditional Uses, Phytochemistry, Pharmacology, Pharmacokinetics And Toxicology of the Genus Peganum. J. Ethnopharmacol. 2017, 203, 127-162.

(14) Cheng, X. M.; Zhao, T.; Yang, T.; Wang, C. H.; Bligh, S. W.; Wang, Z. T. HPLC Fingerprints Combined with Principal Component Analysis, Hierarchical Cluster Analysis and Linear Discriminant Analysis for the Classification and Differentiation of Peganum sp. Indigenous to China. Phytochem. Anal. 2010, 21, 279289.

(15) Li, Y.; Zhang, Y.; Tuniyazi, G.; Mulatibieke, D.; Malike, D.; He, Q.; Geng, Z. Optimization of the Extraction Technology of Antioxidant Substances from the Peganum harmala L. by Uniform Design. Hans J. Comput. Biol. 2019, 3, 52-58.

(16) Li, Y.; He, Q.; Geng, Z.; Du, S.; Deng, Z.; Hasi, E. NMR-based Metabolomic Profiling of Peganum harmala L. Reveals Dynamic Variations Between Different Growth Stages. R. Soc. Open Sci. 2018, 5, No. 171722.

(17) Li, Y.; He, Q.; Du, S.; Guo, S.; Geng, Z.; Deng, Z. Study of Methanol Extracts from Different Parts of Peganum harmala L. Using ${ }^{1}$ H-NMR Plant Metabolomics. J. Anal. Methods Chem. 2018, 2018, No. 6532789.

(18) Tugizimana, F.; Piater, L. A.; Dubery, I. A. Plant Metabolomics: A new Frontier in Phytochemical Analysis. S. Afr. J. Sci. 2013, 109, 111.

(19) Li, X.; Luo, H.; Huang, T.; Xu, L.; Shi, X.; Hu, K. Statistically Correlating NMR Spectra and LC-MS Data to Facilitate the Identification of Individual Metabolites in Metabolomics Mixtures. Anal. Bioanal. Chem. 2019, 411, 1301-1309.

(20) Gonzalez-Dominguez, A.; Duran-Guerrero, E.; FernandezRecamales, A.; Lechuga-Sancho, A. M.; Sayago, A.; Schwarz, M.; Segundo, C.; Gonzalez-Dominguez, R. An Overview on the Importance of Combining Complementary Analytical Platforms in Metabolomic Research. Curr. Top. Med. Chem. 2017, 17, 3289-3295.

(21) Maroli, A. S.; Gaines, T. A.; Foley, M. E.; Duke, S. O.; Doğramaci, M.; Anderson, J. V.; Horvath, D. P.; Chao, W. S.; Tharayil, N. Omics in Weed Science: A Perspective from Genomics, Transcriptomics, and Metabolomics Approaches. Weed Sci. 2018, 66, 681-695.

(22) Akiyama, K.; Chikayama, E.; Yuasa, H.; Shimada, Y.; Tohge, T.; Shinozaki, K.; Hirai, M. Y.; Sakurai, T.; Kikuchi, J.; Saito, K. PRIMe: A Web Site that Assembles Tools for Metabolomics and Transcriptomics. In Silico Biol. 2008, 8, 339-345.

(23) Wishart, D. S.; Tzur, D.; Knox, C.; Eisner, R.; Guo, A. C.; Young, N.; Cheng, D.; Jewell, K.; Arndt, D.; Sawhney, S.; et al. HMDB: The Human Metabolome Database. Nucleic Acids Res. 2007, $35,521-526$

(24) Nepali, K.; Sharma, S.; Ojha, R.; Dhar, K. L. Vasicine and Structurally Related Quinazolines. Med. Chem. Res. 2013, 22, 1-15.

(25) Barker, M.; Rayens, W. Partial Least Squares For Discrimination. J. Chemom. 2003, 17, 166-173.

(26) Moon, J.; Shibamoto, T. Antioxidant Assays for Plant and Food Components. J. Agric. Food Chem. 2009, 57, 1655-1666.

(27) Sodaeizadeh, H.; Rafieiolhossaini, M.; Havlík, J.; Van Damme, P. Allelopathic Activity of Different Plant Parts of Peganum harmala L. and Identification of Their Growth Inhibitors Substances. Plant Growth Regul. 2009, 59, 227-236.

(28) Nitschke, U.; Stengel, D. B. Iodine Contributes to Osmotic Acclimatisation in the Kelp Laminaria digitata (Phaeophyceae). Planta 2014, 239, 521-530.

(29) Pang, Q.; Zhang, A.; Zang, W.; Wei, L.; Yan, X. Integrated Proteomics and Metabolomics for Dissecting the Mechanism of Global Responses to Salt and Alkali Stress in Suaeda corniculata. Plant Soil 2016, 402, 379-394.

(30) Nemat Alla, M. M.; Khedr, A. H. A.; Serag, M. M.; Abu-Alnaga, A. Z.; Nada, R. M. Regulation of Metabolomics in Atriplex halimus Growth under Salt and Drought Stress. Plant Growth Regul. 2012, 67, 281-304. 
(31) Foyer, C. H.; Shigeoka, S. Understanding Oxidative Stress and Antioxidant Functions to Enhance Photosynthesis. Plant Physiol. 2011, 155, 93-100.

(32) Jithesh, M. N.; Prashanth, S. R.; Sivaprakash, K. R.; Parida, A. $\mathrm{K}$. Antioxidative Response Mechanisms in Halophytes: Their Role in Stress Defence. J. Genet. 2006, 85, 237-254.

(33) Sairam, R. K.; Srivastava, G. C. Changes in Antioxidant Activity in Sub-cellular Fractions of Tolerant and Susceptible Wheat Genotypes in Response to long Term Salt Stress. Plant Sci. 2002, 162, 897-904.

(34) Chen, L. L.; Shan, W.; Cai, D. L.; Chen, J. Y.; Lu, W. J.; Su, X. G.; Kuang, J. F. Postharvest Application of Glycine Betaine Ameliorates Chilling Injury in Cold-stored Banana Fruit by Enhancing Antioxidant System. Sci. Hortic. 2021, 287, No. 110264.

(35) Kosová, K.; Prášil, I.; Vítámvás, P. Protein Contribution to Plant Salinity Response and Tolerance Acquisition. Int. J. Mol. Sci. 2013, 14, 6757-6789.

(36) Guo, J.; Muhammad, H.; Lv, X.; Wei, T.; Ren, X.; Jia, H.; Atif, S.; Hua, L. Prospects and Applications of Plant Growth Promoting Rhizobacteria to Mitigate Soil Metal Contamination: A Review. Chemosphere 2020, 246, No. 125823.

(37) Wen, F.; Cheng, X.; Liu, W.; Xuan, M.; Zhang, L.; Zhao, X.; Shan, M.; Li, Y.; Teng, L.; Wang, Z.; Wang, C. Chemical Fingerprint and Simultaneous Determination of Alkaloids and Flavonoids in Aerial Parts of Genus Peganum Indigenous to China Based on HPLCUV: Application of Analysis on Secondary Metabolites Accumulation. Biomed. Chromatogr. 2014, 28, 1763-1773.

(38) Sakurai, T.; Yamada, Y.; Sawada, Y.; Matsuda, F.; Akiyama, K.; Shinozaki, K.; Hirai, M. Y.; Saito, K. PRIMe Update: Innovative Content for Plant Metabolomics and Integration of Gene Expression and Metabolite Accumulation. Plant Cell Physiol. 2013, 54, No. e5.

(39) Kim, H. K.; Choi, Y. H.; Verpoorte, R. NMR-Based Metabolomic Analysis of Plants. Nat. Protoc. 2010, 5, 536-549.

(40) Foti, M. C. Use and Abuse of the DPPH ${ }^{\bullet}$ Radical. J. Agric. Food Chem. 2015, 63, 8765-8776. 